\title{
A Design of Optimal Interval between Armatures in Long Distance Transportation PMLSM for End Cogging Force Reduction
}

\author{
Eui-Jong Park*, Sang-Yong Jung** and Yong-Jae Kim ${ }^{\dagger}$
}

\begin{abstract}
Although the permanent magnet linear synchronous motor is a motor useful for transportation systems thanks to its high speed, high acceleration and deceleration, the linear motor generally has armatures installed on the full length of the transport path. It results in the increase in material costs and manufacturing time. As a means to solve this problem a stationary discontinuous armature system is suggested. However, it involves the following two issues. The first issue is it is impossible to control the mover in the section where any armature is not installed as armatures are distributed. The second one is increasing cogging force due to the ends of the armatures. Therefore, this study aims to solve these problems by adjusting intervals between armatures to control the mover anywhere, and to design the interval between armatures optimally to minimize the end cogging force. The suitable distance was deduced. It addressed the problems and showed suitability for long distance transportation PMLSM.
\end{abstract}

Keywords: Discontinuous armature, End cogging force, Interval between armature modules, Long distance transportation

\section{Introduction}

Rectilinear motion through a rotating machine requires gears, for example, ball screws, racks and pinions. However, generated heat and abrasion due to friction that occurs in gear engagement, and backlashes due to gaps of gears increase loss and decrease precision.

The permanent magnet linear synchronous motor (PMLSM) implements rectilinear motion without gears which function as a mechanical converter for rectilinear motion, and is a motor useful for transportation systems thanks to its high speed, high acceleration and deceleration $[1,2]$. However, because of increased transportation distance in linear motors for which armatures must be installed in the full length of transportation lines, increased material costs and time for manufacturing thereof are inevitable [3]. The discontinuous arrangement system of stationary armature (DAS) has been suggested to install armatures only in the section for which acceleration and deceleration of a mover is necessary to address the aforementioned issue [4].

While the DAS can minimize the increased material costs and time for manufacturing of the PMLSM as transportation distance increases, it involves the following two issues. The first issue is it is impossible to control the mover in the section where any armature is not installed as

$\dagger$ Corresponding Author: Dept. of Electrical Engineering, Chosun University, Korea. (kimyj21@chosun.ac.kr)

* Dept. of Electrical Engineering, Chosun Univerity, Korea. (puj1988@hanmail.net)

** School of Electronic and Electrical Engineering, Sungkyunkwan University, Korea. (syjung@skku.edu)

Received: June 25, 2015; Accepted: October 7, 2015 armatures are distributed, and the second one is increasing cogging force due to the ends of the armatures. Therefore, this study aims to conduct 2-D numerical analysis with FEM for cogging force characteristics of the DAS, and improve the uncontrollable area by adjusting the intervals for arranging armatures. Another aim is to find out interval between armature modules to minimize end cogging force.

\section{Discontinuous Armature PMLSM}

\subsection{Long distance transportation PMLSM}

A transportation system which employs a PMLSM uses a continuous arrangement system of stationary armature (CAS) for which armatures are installed in the full length of transportation lines, as shown in Fig. 1(a). Installing armatures in the full length of transportation lines entails increased use of electrical steel sheets and coils, and other installations as transportation distance increases. This

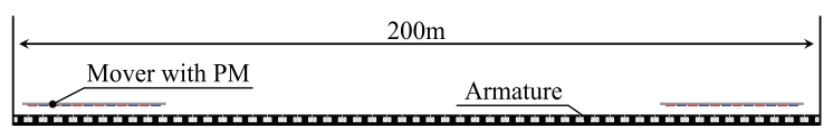

(a)

Armature module(9slot )
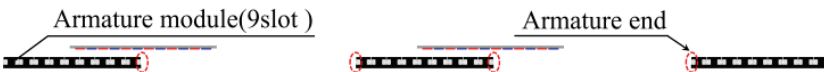

(b)

Fig. 1. Method of armature arrangement: (a) Continuous arrangement system and (b) Discontinuous arrangement system 
Table 1. Reduction ratio of used electrical steel sheet depending on the armature interval

\begin{tabular}{c|c|c|c}
\hline & $\begin{array}{c}\text { Armature } \\
\text { modules [units] }\end{array}$ & $\begin{array}{c}\text { Slots } \\
\text { [slots] }\end{array}$ & $\begin{array}{c}\text { Reduction ratio of } \\
\text { electrical steel sheets[\%] }\end{array}$ \\
\hline CAS & - & 5,000 & - \\
\hline $\begin{array}{c}\text { DAS (armature } \\
\text { interval: 1m) }\end{array}$ & 147 & 1,323 & 73.54 \\
\hline $\begin{array}{c}\text { DAS (armature } \\
\text { interval: 5m) }\end{array}$ & 38 & 342 & 93.16 \\
\hline
\end{tabular}

increases the material costs and time for manufacturing of the installations. Because of more material costs and time for manufacturing, the transportation system which uses a PMLSM is usually used for short-distance or limited longdistance transportation systems. For addressing the issues, the DAS shown in Fig. 1(b) has been suggested. The DAS employs armatures installed just in the section which needs mover acceleration and deceleration, and can minimize the increase of material costs and time for manufacturing depending on the distance. If armatures of which the slot pitch is $40 \mathrm{~mm}$ are installed in $200 \mathrm{~m}$ of transportation lines, the continuous arrangement armature system needs 5,000 slots. The DAS of which one armature module has 9 slots $(360 \mathrm{~mm})$ and interval between armature modules is $1 \mathrm{~m}$ requires 1,323 slots. If the interval between armatures is $5 \mathrm{~m}, 342$ slots are required. This implies reduction of electrical steel sheets of $73.54 \%$ and $93.16 \%$, respectively, in comparison with the continuous arrangement armature system. Table 1 shows reduced electrical steel sheets depending on the intervals of armatures.

\subsection{Uncontrollable section in DAS}

One of the important things in a transportation system is to move an object to a target location within a specified time. If the system stops due to external forces or problems therein, it should be possible to supply driving force for restart in any part of the transportation lines as long as it is not a breakdown. However, the DAS can supply thrust magnetic field which is driving force just in the section where armatures are installed. As such, discontinuous supply of driving force makes it difficult to restart the stationary mover. In particular, if the mover stops in a section where armatures are not installed in the system in which interval between armature modules is established longer than the mover length, an additional tow system is required to drive the mover. Accidents can then happen because of time delay for response.

To address this issue, it is necessary to make interval between armature modules shorter than the mover length so that the mover can always respond to a given part of the armatures. However, as the mover is short or the part thereof responding to the armature increases, interval between armature modules decreases to reduce the effect of distributed armatures. If an 8-pole $(240 \mathrm{~mm})$ mover and a 9 -slot $(1$ module $=360 \mathrm{~mm})$ armature module are used and interval between armature modules is assumed $200 \mathrm{~mm}$ to apply $200 \mathrm{~m}$ to the transportation lines, 3,213 slots are required. This is a value $35.74 \%$ smaller than 5,000 slots used in the continuous arrangement armature system, which implies the reduction ratio well below a half. Therefore, the target in this study is to reduce the number of armature modules used in the DAS for long-distance transportation by more than $50 \%$. It is essential that interval between armature modules is shorter than $360 \mathrm{~mm}$ which is a length of one armature module in order to reduce the number of used armature modules by more than $50 \%$. Therefore, in this study, the mover length is defined as the length equal to 3 times the length of an armature module.

\subsection{End cogging force}

Cogging force accelerates the mover as a positive value if it occurs in the direction the same as the direction of the mover in motion. If it occurs in the direction opposite to the direction of the mover in motion, it is a negative value to decelerate the mover. Such cogging force occurs due to armature teeth ends and the end of permanent magnet teeth to have a given cycle.

However, because the mover travels between armature modules in the DAS, it is essential to consider the cogging force by both ends of the permanent magnet of the mover and the armature module. This is referred to as end cogging force. The waveform of end cogging force by means of each pole with which the mover enters and comes out of the armature becomes great in the single direction, and is irregular without periodicity.

The aforementioned nature of end cogging force contributes to representing the same amount of force as the direction of the mover in motion when it enters the armature to accelerate the mover. On the other hand, it is just a negative force opposite to the direction of the mover in motion to decelerate the mover when it comes out of the armature.

In this study, two armature modules were arranged at an interval of $360 \mathrm{~mm}$ equal to the length of one armature module in order to analyze cogging force depending on mover positions. The mover length was defined as $1080 \mathrm{~mm}$ equal to 3 times the length of an armature module defined in the above. A permanent magnet of 36 poles was arranged in the mover to set it as a base model. The 2-D numerical analysis with FEM for analyzing cogging force was to establish $5 \mathrm{~mm}$ for the gap between the mover and the armatures, and to move the mover at intervals of $1 \mathrm{~mm}$ until it entered the first armature module and then came out of the second armature module. The number of nodes of the numerical analysis model is 143,938 , and the number of elements is 275,550 . Table 2 shows the specifications of PMLSM for armature arrangement. Fig. 2 shows the characteristics of cogging force of the DAS with interval between armature modules $360 \mathrm{~mm}$. 
Table 2. Specifications of PMLSM

\begin{tabular}{c|c|c}
\hline \multicolumn{2}{c|}{ Items } & Value \\
\hline \multirow{4}{*}{ Mover } & Height of PM & $3 \mathrm{~mm}$ \\
\cline { 2 - 3 } & Length of PM & $26 \mathrm{~mm}$ \\
\cline { 2 - 3 } & The number of PM & 36 poles \\
\cline { 2 - 3 } & Pole pitch & $30 \mathrm{~mm}$ \\
\cline { 2 - 3 } Armature & Back iron height & $6 \mathrm{~mm}$ \\
\hline \multirow{5}{*}{} & Coil turns per phase & $75 \mathrm{turns}$ \\
\cline { 2 - 3 } & Slot pitch & $40 \mathrm{~mm}$ \\
\cline { 2 - 3 } & Slot width & $24 \mathrm{~mm}$ \\
\cline { 2 - 3 } & Slots of armature module & $9 \mathrm{slots}$ \\
\cline { 2 - 3 } & Width of teeth & $16 \mathrm{~mm}$ \\
\cline { 2 - 3 } & Height of teeth & $5 \mathrm{~mm}$ \\
\hline
\end{tabular}

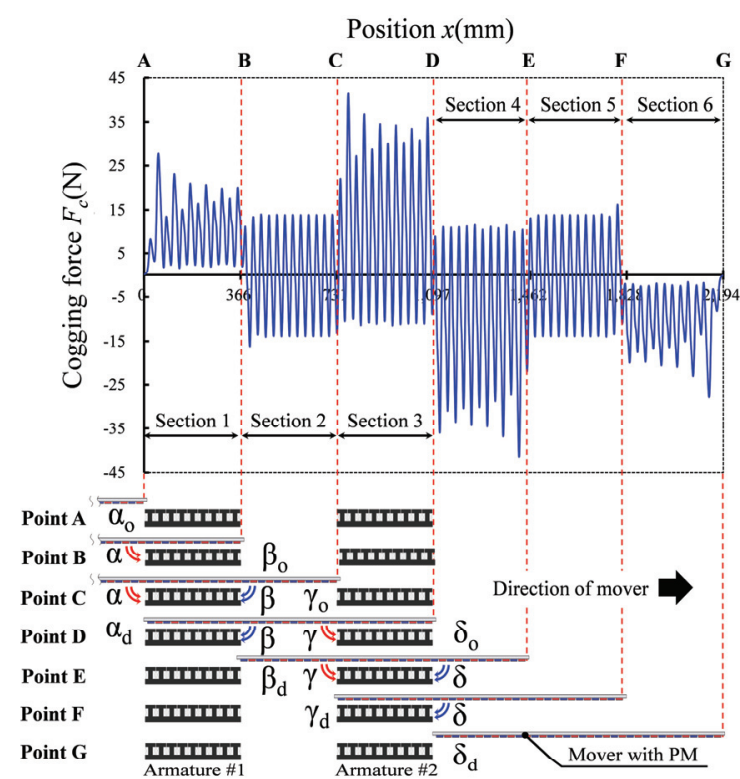

Fig. 2. Cogging force of novel discontinuous arrangement armature system

In Fig. 2, the points $A-G$ represent the positions of the mover, and $\alpha-\delta$ represent end cogging force due to the ends of armatures. Here, $\alpha$ is end cogging force which occurs when the mover enters the first armature; $\beta$ is end cogging force which occurs when it comes out of the first armature; $\gamma$ is end cogging force which occurs when the mover enters the second armature; and $\delta$ is end cogging force which occurs when it comes out of the second armature. Accordingly, $\alpha$ and $\gamma$ produce positive force, but $\beta$ and $\delta$ produce negative force. The sections 1-6 are positioned depending on the relation between points A-G and forces $\alpha-\delta$, and Table 3 shows their definition.

The subscript 'o' of $\alpha-\delta$ which represents cogging force due to the end of armatures implies the point right before end cogging force occurs, and the subscript ' $d$ ' represents the point right after end cogging force disappears. Therefore, section 1 is from point $A$ to point $B$, where force $\alpha$ occurs. Section 2 is from point $B$ to point $C$, where forces $\alpha$ and $\beta$ concurrently occur. Section 3 is from point $C$ to point $\mathrm{D}$, where forces $\alpha, \beta$ and $\gamma$ concurrently occur.
Section 4 is from point $\mathrm{D}$ to point $\mathrm{E}$, where forces $\beta, \gamma$ and $\delta$ concurrently occur. Section 5 is from point $E$ to point $F$, where forces $\gamma$ and $\delta$ concurrently occur. Section 6 is from point $\mathrm{F}$ to point $\mathrm{G}$, where force $\delta$ just occurs.

Through the analyzed cogging force waveforms, great cogging force was identified to occur in section 1 where the mover entered the first armature; section 3 where it entered the second armature; section 4 where it came out of the first armature; and section 6 where it came out of the second armature, depending on the characteristics of end cogging force, and there was no periodicity.

\section{End Cogging Force Reduction Method of DAS}

\subsection{Characteristic analysis of end cogging force in DAS}

End cogging force is the force which causes vibration and noise of the mover, and should be reduced. Therefore, a method was devised to control interval between armature modules in order to reduce end cogging force of the DAS. An analysis is made of the characteristics of end cogging force which occurs in each section to minimize end cogging force by removing the factors which contribute to increasing end cogging force.

Before analyzing end cogging force of the DAS, the actual driving section of PMLSM is from section 2 to 5 . Therefore, the cogging force in sections 1, 6 does not have an effect on the motor's performance and not need to be reduced. However, these sections need in order to analyze and understand the other sections (sections 2-5) like a used the $\alpha$ and $\delta$. Also, sections 1, 2 and 3 are analyzed because sections 1, 2 and 3 and sections 4,5 and 6 show symmetrical waveforms each other in Fig. 2. Among these sections, 1 and 6 are not operating region. They are just used for explaining the end cogging force phenomenon between armature and magnet. Therefore, end cogging force of the sections 1 and 6 do not need to reduce.

Referring to the description in 2.3, force $\alpha$ just occurs in section 1 ; forces $\alpha$ and $\beta$ concurrently occur in section 2 ; and forces $\alpha, \beta$ and $\gamma$ concurrently occur in section 3. A focus is laid on section 3 where the greatest end cogging force $41.46 \mathrm{~N}$ occurs across the entire sections. Fig. 3 shows the effect of cogging force due to armature end in section 3 .

The method of analysis in this study is to divide end cogging force into the end cogging force that occurs by means of the first armature and the end cogging force that occurs by means of the second armature in order to analyze the end cogging force that occurs in section 3 .

First, the end cogging force that occurs by means of the first armature is forces $\alpha$ and $\beta$ that occur while the mover moves from point $\mathrm{C}$ to point $\mathrm{D}$. The section where the same force occurs is found in Table 3 , and the force is equal to end cogging force that occurs in section 2 . 
Table 3. Sections 1-6 according to points A-G and end cogging force $\alpha-\delta$

\begin{tabular}{c|c|c|c|c|c|c|c|c}
\hline \multirow{2}{*}{ Section } & \multicolumn{2}{|c|}{ Section 1} & \multicolumn{2}{c|}{ Section 3 } & \multicolumn{2}{c|}{ Section 5 } & \\
\cline { 2 - 8 } & & \multicolumn{2}{|c|}{ Section 2 } & \multicolumn{2}{c}{ Section 4 } & \multicolumn{2}{c}{ Section 6 } \\
\hline Point & $\mathrm{A}$ & $\mathrm{B}$ & $\mathrm{C}$ & $\mathrm{D}$ & $\mathrm{E}$ & $\mathrm{F}$ & $\mathrm{G}$ \\
\hline \multirow{3}{*}{$\begin{array}{c}\text { End cogging } \\
\text { force }\end{array}$} & $\alpha_{\mathrm{o}}$ & $\alpha$ & $\alpha$ & $\alpha_{\mathrm{d}}$ & $\cdot$ & $\cdot$ & $\cdot$ \\
\cline { 2 - 8 } & $\cdot$ & $\beta_{\mathrm{o}}$ & $\beta$ & $\beta$ & $\beta_{\mathrm{d}}$ & $\cdot$ & $\cdot$ \\
\cline { 2 - 8 } & $\cdot$ & $\cdot$ & $\gamma_{\mathrm{o}}$ & $\gamma$ & $\gamma$ & $\gamma_{\mathrm{d}}$ & $\cdot$ \\
\cline { 2 - 8 } & $\cdot$ & $\cdot$ & $\cdot$ & $\delta_{\mathrm{o}}$ & $\delta$ & $\delta$ & $\delta_{\mathrm{d}}$ \\
\hline
\end{tabular}

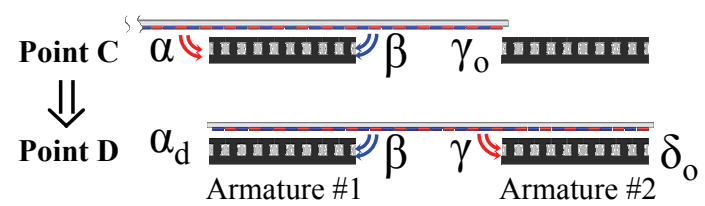

Fig. 3. End cogging force generated by armature end in section 3

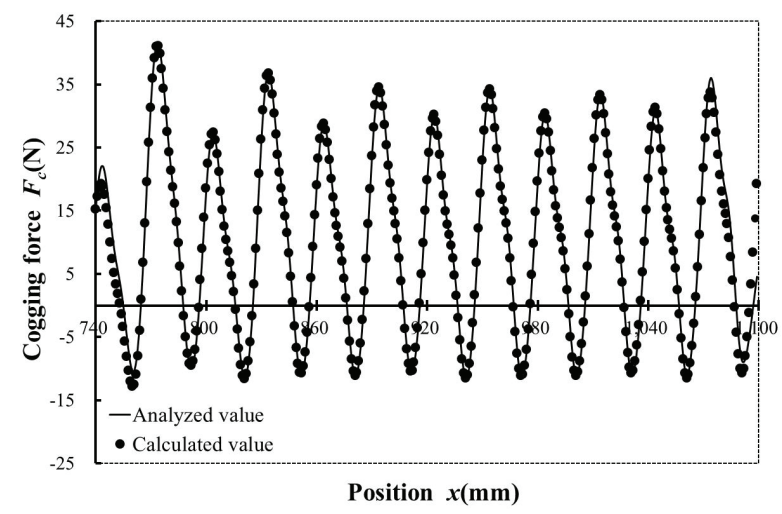

Fig. 4. Comparison of Analyzed and calculated value on the section 3

Next, the end cogging force that occurs due to the second armature is force $\gamma$ while the mover moves from point $\mathrm{C}$ to point $\mathrm{D}$. Force $\gamma$ is end cogging force that occurs when the mover enters the armature, and equal to force $\alpha$ which is the end cogging force that occurs when the mover enters the first armature. Therefore, the section where the same force occurs is found in Table 3, and the force is equal to the end cogging force that occurs in section 1.

Generalizing the findings from the analysis, the end cogging force that occurs in section 3 is divided into the end cogging force that occurs in section 2 and the end cogging force that occurs in section 1, represented by (1).

$$
\begin{aligned}
\mathrm{F}_{\mathrm{ec}}(\text { section } 3) & =(\alpha+\beta)+\gamma,(\gamma=\alpha) \\
& =\mathrm{F}_{\mathrm{ec}}(\text { section } 2)+\mathrm{F}_{\mathrm{ec}}(\text { section } 1)
\end{aligned}
$$

where, $F_{\text {ec }}$ is end cogging force. Fig. 4 shows the end cogging force in section 3 by numerical analysis, and the end cogging force in section 3 by the sum of end cogging force in sections 1 and 2 according to (1) in order to prove the end cogging force in section 3 by (1). Fig. 4 shows the end cogging force in section 3 is equal to the sum of end

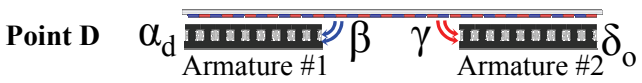

(a)

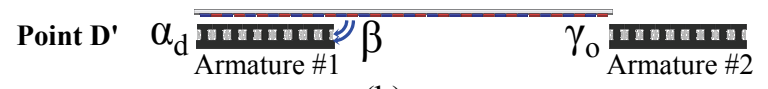

(b)

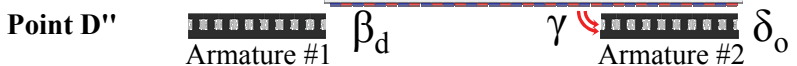

(c)

Fig. 5. Adjustment of distance between armature modules to remove the $\gamma$ (a) End cogging force generated by armature end in, (b) End cogging force generated by armature end in point $\mathrm{D}^{\prime}$ and (c) End cogging force generated by armature end in point $\mathrm{D}^{\prime \prime}$

cogging force in sections 1 and 2 .

\subsection{End cogging force reduction using adjustment of interval between armatures}

It is seen the end cogging force in section 3 is equal to the sum of the end cogging force in sections 1 and 2 as shown in Fig. 4 of 3.1.

Increasing positive cogging force in section 3 is contributed to by the mover entering two armatures, that is, concurrent occurrence of forces $\alpha$ and $\gamma$. Therefore, interval between armature modules was controlled so that one of forces $\alpha$ and $\gamma$ can occur in order to reduce positive cogging force in section 3 .

First, Fig. 5(a) shows point $\mathrm{D}$ which is the limit where forces $\alpha, \beta$ and $\gamma$ concurrently occur, and the second armature was moved to the point where force $\gamma$ occurred. The mover position in this case is point $\mathrm{D}^{\prime}$. At point $\mathrm{D}^{\prime}$, force $\gamma$ does not occur before the mover enters the second armature, and forces $\alpha$ and $\beta$ are exerted. The mover position changes to $\mathrm{D}$ " as the mover moves as shown in 5(c), where force $\alpha$ does not occur, but forces $\beta$ and $\gamma$ are exerted.

Therefore, as shown in Fig. 5(b) and (c), the maximum distance of interval between armature modules where one of forces $\alpha$ and $\gamma$ occurs is the same as the value by subtracting the length of one armature module from the mover length, which is represented with (2).

$$
\begin{gathered}
\mathrm{I}_{\mathrm{ba}}<\mathrm{L}_{\mathrm{m}}-\mathrm{L}_{\mathrm{a}} \text {, when } \gamma>0 \\
\mathrm{I}_{\mathrm{ba}}>=\mathrm{L}_{\mathrm{m}}-\mathrm{L}_{\mathrm{a}} \text {, when } \gamma=0
\end{gathered}
$$

where, $\mathrm{I}_{\mathrm{ba}}$ is distance between armature modules, $\mathrm{L}_{\mathrm{m}}$ is Length of mover and $L_{a}$ is Length of armature module. Therefore, substituting mover length $1,080 \mathrm{~mm}$ and armature length $360 \mathrm{~mm}$ of this model for (2) results in interval between armature modules $720 \mathrm{~mm}$ where one of forces $\alpha$ and $\gamma$ occurs. The derived interval between armature modules $720 \mathrm{~mm}$ was applied to the DAS to 


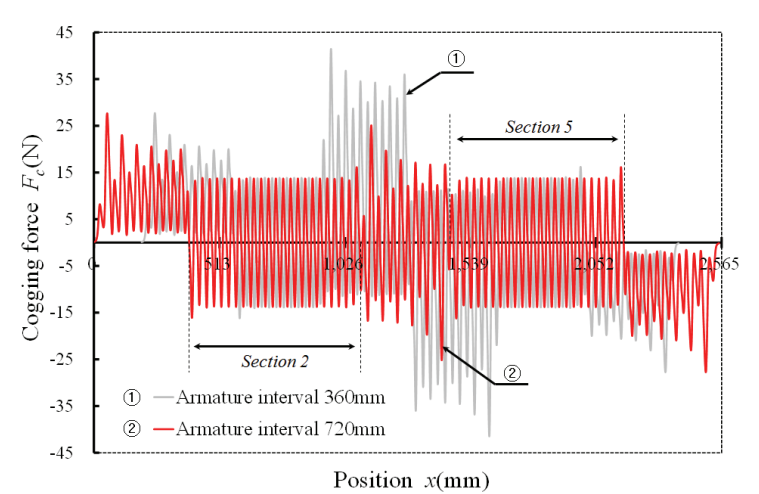

Fig. 6. Cogging force comparison with armature interval $720 \mathrm{~mm}$

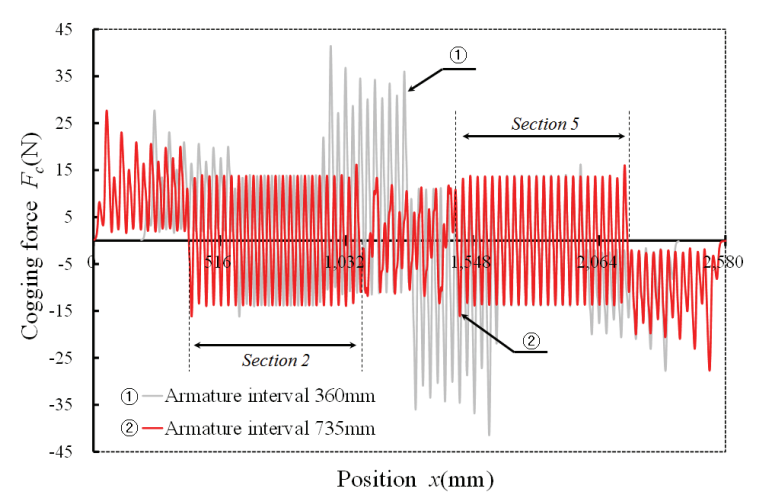

Fig. 7. Cogging force comparison with armature interval $735 \mathrm{~mm}$

conduct 2-D numerical analysis from the point where the mover enters the first armature module to the point where it comes out of the second armature module. The number of nodes of the numerical analysis model is 174,177 and the number of elements is 332,178. Fig. 6 shows the waveform of cogging force characteristics of numerical analysis. The maximum end cogging force that occurs between sections 2 and 5 in Fig. 6 is $\pm 25.09 \mathrm{~N}$ which is $40 \%$ smaller than the maximum end cogging force that occurred between sections 2 and 5 of the interval between armature modules $360 \mathrm{~mm}$ model.

End cogging force was reduced by $40 \%$ by controlling interval between armature modules in comparison with interval between armature modules $360 \mathrm{~mm}$. However, the maximum cogging force between sections 2 and 5 is greater than the maximum cogging force in sections 2 and 5 by at least $10 \mathrm{~N}$. Therefore, it is necessary to further study how to reduce it. A method of reducing cogging force is suggested by crossing the position of the core and the permanent magnet of the armature each other by a half cycle of cogging force to offset the cogging force [5]. The armature was moved by $15 \mathrm{~mm}$ which is a half of the pole pitch $30 \mathrm{~mm}$ to analyze the effect of end cogging force in order to forward the cycle of end cogging force cross by a half cycle. The 2-D numerical analysis was conducted by applying interval between armature modules $735 \mathrm{~mm}$ and while the mover entered the first armature module and then came out of the second armature module. The number of nodes in the numerical analysis model was 175,212 , and the number of elements was 334,083 . The waveform of cogging force characteristics of numerical analysis is shown in Fig. 7.

In Fig. 7, the maximum end cogging force that occurred between sections 2 and 5 is offset to be reduced, and $13.40 \mathrm{~N}$ which is $67.7 \%$ smaller than the maximum end cogging force that occurred between sections 2 and 5 of the interval between armature modules $360 \mathrm{~mm}$ model. Therefore, interval between armature modules to minimize end cogging force of the DAS by controlling interval between armature modules is obtained with the following (3).

$$
\mathrm{I}_{\mathrm{ba}}=\mathrm{L}_{\mathrm{m}}-\mathrm{L}_{\mathrm{a}}+\tau_{\mathrm{c}} / 2
$$

where $\tau_{\mathrm{c}}$ is pole pitch.

\section{Conclusion}

This study suggests a DAS to address the issues of increased material costs and time for manufacturing in order to apply the PMLSM to a long-distance transportation system. Ideal interval between armature modules is found out to minimize cogging force by determining mover length, analyzing cogging force depending mover positions and controlling interval between armature modules in order to address the issues of DAS end cogging force and uncontrollable sections.

The mover length is first controlled to be equal to 3 times the length of an armature module to make the mover and the armature interact in any section. The finding in this study through cogging force analysis is the great positive cogging force that occurs in the section where end cogging force concurrently occurs in 3 points is the result of the mover's simultaneously entering the first armature and the second armature. End cogging force is reduced by the method of removing the effect of the second armature while sticking to the effect of the first armature in order to reduce the positive cogging force in this section. The armature was moved by $1 / 2$ of the pole pitch to make the end cogging force cycle forward by a half cycle to offset cogging force and thus to minimize cogging force. As a result, the maximum end cogging force with interval between armature modules $735 \mathrm{~mm}$ was $13.40 \mathrm{~N}$ which is $67.7 \%$ smaller than the maximum end cogging force $41.46 \mathrm{~N}$ with interval between armature modules $360 \mathrm{~mm}$.

The method suggested in this study can address the issue of uncontrollable sections and increased end cogging force involved in a conventional DAS by addressing DAS interval between armature modules, and derive the intervals between armatures to minimize end cogging force. 


\section{Acknowledgements}

This work was supported by the Human Resource Training Program for Regional Innovation and Creativity through the Ministry of Education and National Research Foundation of Korea. (NRF-2014H1C1A1066713)

\section{References}

[1] K. C. Lim, J.K. Woo, G. H. Kang, J. P. Hong, and G. T. Kim, "Detent force minimization techniques in permanent magnet linear synchronous motor," IEEE Trans. on Magn., Vol. 38, No. 2, pp. 1157-1160, 2002.

[2] R. Hellinger, and P. Mnich, "Linear motor-powered transportation: history, present status, and future outlook," Proc. of the IEEE, Vol. 97, No. 11, pp. 1892-1900, 2009.

[3] Ruiwu Cao, Ming Cheng, Mi, C.C., Wei Hua, "Influence of leading design parameters on the force performance of a complementary and modular linear flux-switching permanent-magnet motor," Trans. Ind. Electron., Vol. 61, Is. 5, pp. 2165-2175, 2014.

[4] Y. Kim, and H. Dohmeki, "Driving characteristics analysis of stationary discontinuous armature permanent magnet linear synchronous motor for factory automation systems," Electrical engineering, Vol. 89, No. 8, pp. 617-627, 2007.

[5] T. Yoshimura, H.J. Kim, M. Watada, S. Torii, D. Ebihara, "Analysis of the reduction of detent force in a permanent magnet linear synchronous motor," IEEE Trans. On Magn., Vol. 31, No. 6, pp. 3728-3730, 1995.

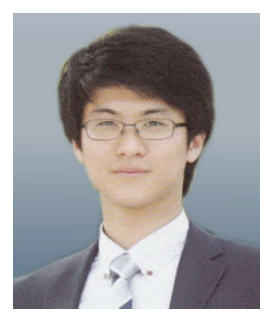

Eui-Jong Park He received B.S and M.S degree in department of electrical engineering from Chosun University, Gwang-ju, Korea in 2013 and 2015, respectively. Since 2015, he is doing a Ph.D course in department of electrical engineering from Chosun University, Gwang-ju, Korea. His research interests are numerical analysis and design of linear machineries and PM machineries.

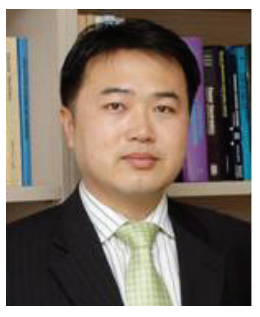

Sang-Yong Jung He received the B.S., M.S.,and Ph.D. degrees in electrical engineering from Seoul National University, Seoul, Korea, in 1997, 1999, and 2003, respectively. From 2003 to 2006, he was a Senior Research Engineer with the R\&D Division, Hyundai Motor Company, Korea, and the R\&D Division, Kia Motor, Korea. From 2006 to 2011, he was an Assistant Professor with the Department of Electrical Engineering, Dong-A University, Busan, Korea. He is currently an Associate Professor with the School of Information and Communication Engineering, Sungkyunkwan University, Suwon, Korea. His research interests include the numerical analysis and optimal design of electric machines and power apparatus.

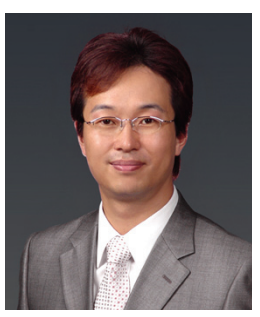

Yong-Jae Kim He received B.S degree in department of electrical engineering from Chosun University, Gwang-ju, Korea in 1996 and the M.S, Ph.D degree in electrical engineering from Musashi Institute of Technology, Tokyo, Japan, in 2003 and 2006, respectively. From 2006 to 2007, he was a Researcher of electrical and electronic engineering with the Musashi Institute of Technology, Tokyo, Japan. He is currently an Associate Professor with the Department of Electrical Engineering, Chosun University, Gwangju, Korea. His current research interests include the design and analysis of electric machines. 